\title{
Control of Chronic Obstructive Pulmonary Disease in Urban Populations: Findings From a Cross- Sectional Prevalence Survey in Shenzhen, China
}

\section{Le-Cai Ji}

Chronic Disease Control of Shenzhen

Jin-Feng Yin

Capital Medical University

Chun-Rong Lu

Chronic Disease Control of Shenzhen

Hong-Yun Guan

Chronic Disease Control of Shenzhen

Wei-Guo Tan

Chronic Disease Control of Shenzhen

Ling-Wei Wang

Shenzhen People's Hospital

Qi Jiang ( $\boldsymbol{D}_{\text {jiang.qi@whu.edu.cn ) }}$

Wuhan University https://orcid.org/0000-0002-3872-6312

\section{Research}

Keywords: Chronic obstructive pulmonary disease, Prevalence survey, Spirometry

Posted Date: April 6th, 2021

DOl: https://doi.org/10.21203/rs.3.rs-373932/v1

License: (9) (i) This work is licensed under a Creative Commons Attribution 4.0 International License.

Read Full License 


\section{Abstract \\ Background}

Lower is the prevalence of chronic obstructive pulmonary disease (COPD) among urban populations, but still high is the total burden. Limited evidence on the patients' characteristics has been offered to guide the control of the disease in city settings.

\section{Methods}

We conducted a prevalence cross-sectional survey of COPD among residents aged $\geq 40$ years in an emerging city Shenzhen, China. The multi-stage stratified random sampling method was applied to enroll eligible participants from September, 2018 to June, 2019. Tested by spirometry, individuals were diagnosed with COPD if the post-bronchodilator FEV1/FVC ratio was less than 0.7. Patients' demographic and clinical characteristics, as well as estimates of the exposure to air pollutants, were included in the univariable and multivariable logistic regression models to assess the risk factors for COPD.

\section{Results}

A total of 4157 individuals were invited to participate in this survey and 3591 who had available spirometry results and epidemiological data were enrolled in the final analysis. The estimated standardized prevalence of COPD among residents over 40 years old in Shenzhen was $5.92 \%$ (95\% confidential intervals 4.05-8.34). Risk factors for COPD included elder age (adjusted odds ratio 1.206, 95\% Cl 1.120-1.299 per 10-year increase), smoking over 20 pack-years (1.968, 1.367-2.832), history of chronic bronchitis $(1.733,1.036-2.900)$ or asthma $(4.920,2.425-9.982)$, and exposure to higher annual minimum concentrations of ambient $\mathrm{SO}_{2}\left(1.156,1.053-1.270\right.$ per $1-\mu \mathrm{g} / \mathrm{m}^{3}$ increase). Among 280 spirometry-diagnosed patients, most $(221,78.93 \%)$ patients were classified as mild COPD (GOLD stage I). The COPD assessment tests showed $24.7 \%$ (58/235) patients had severe symptoms with a total score $\geq$ 10 , and $82.6 \%(194 / 235)$ were clinically symptomatic with a total score $\geq 2$.

\section{Conclusions}

This survey found a low prevalence of COPD in Shenzhen and most patients had mild symptoms, thus recommended screening using spirometry in primary health care to detect early-stage COPD. Increased risk from the exposure to air pollutants also indicated the urgent need for environmental improvement in city settings.

\section{Background}


Chronic obstructive pulmonary disease (COPD) is a preventable and curable respiratory disease characterized by persistent respiratory symptoms and airflow limitation [1]. COPD is one of the leading causes of death in the world, and the success of its treatment largely depends on the correct implementation of various recommendations, especially effective intervention for early-staged mild diseases [2]. As forecasted by the World Health Organization (WHO), the prevalence of COPD will further increase in the future 40 years because of the increasing smoking rates in developing countries and the aging population in high-income countries [3]. The number of patients who will die from COPD and related diseases would exceed 5.4 million cases globally by 2060 [3]. Variations were observed between the prevalence of COPD in rural and urban areas, but limited evidence was provided to design the targeted measures for different situations.

COPD has been one of the major fatal diseases in China during the past 30 years. Followed to stroke and ischemic heart diseases, the number of patients dying from COPD ranked third in 2017 [4]. A countrywide survey in China during 2014-2015 [5] showed that the prevalence of COPD among residents aged $>40$ years old is $13.6 \%$, which is significantly higher than that in 2007 (8.2\%) [6]. Shenzhen is an economically developed coastal city in southern China, with a better environment than rural areas. A large number of young internal migrants come to this city for more work opportunists and higher income. A pilot survey [7] in a district of Shenzhen showed a COPD prevalence of $9.6 \%$ among residents over 40 years old. People who have related symptoms or exposure to risk factors would be suggested to take the spirometry test every year; however, seldom migrants actively take the examination due to mild symptoms or restricted access to medical service. To make recommendations of control strategies for similar city settings, we conducted a cross-sectional survey in all the ten districts of Shenzhen to estimate the overall prevalence of COPD, to assess associated demographic factors as well as environmental exposure, and to analyze patients' clinical characteristics.

\section{Methods}

\section{Study site}

Shenzhen is a coastal city in southern China and its economy has continuously and prosperously developed over the past 40 years of reform and opening up. A large number of internal migrants have poured into this special economic zone, constituting nearly two-thirds of the 15 million residents in 2020 [8]. This migration resulted in a relatively young residential population in Shenzhen, with an average age of 32.5 years [8]. The city has a tropical oceanic climate with warm and humid air throughout the year. The average temperature in 2019 is $24^{\circ} \mathrm{C}$, and only one day in the whole year had a temperature below $10^{\circ} \mathrm{C}$ [9]. Shenzhen also has good environmental conditions with $43.4 \%$ land of the green area and was titled "the National Forest City" in 2018. The annual average value of $\mathrm{PM}_{2.5}$ is $19 \mu \mathrm{g} / \mathrm{m}^{3}$, and the comprehensive air quality index ranks in the top ten cities in the country [10].

\section{Sampling methods}


In this COPD prevalence survey from September 2018 to June 2019, we enrolled eligible participants $\geq 40$ years old with residence at least six months in Shenzhen using the multi-stage stratified cluster random sampling method. The numbers of communities of each district were determined based on the number of resident populations. A total of 40 communities from ten districts were selected, and about 120 households were selected from each sampled community. The Kish Grid method was used to randomly select one resident over 40 years old from each household for investigation. Excluded were patients with mental illness or cognitive impairment, cancer, high paraplegia, pregnant or breastfeeding women and other subjects who cannot cooperate to complete the epidemiological investigation.

This survey assumes that the prevalence rate is $9.6 \%$ based on the previous survey in Shenzhen [7]. Under the condition that the statistical error probability (a) is 0.05 and the allowable error is $80 \%$, the sample size of each group is estimated to be 1852. Stratified by gender and considering the non-response rate of $15 \%$, the total sample size of the survey is estimated to be 4260 .

\section{Spirometry test and parameters}

Qualified subjects would undergo the pulmonary function test by spirometry and take a structured questionnaire survey after signing the informed consent form. The trained and certified staff used the spirometer (BTL Science and Technology (Shenzhen) Co., Ltd.) to perform pulmonary function examination and bronchodilation test on all the included subjects. The measurement indicators mainly include the forced expiratory volume in one second (FEV1), forced vital capacity (FVC), and one-second rate (FEV1/FVC). Each respondent should successfully complete three pre-bronchiectasis pulmonary function tests, and then perform a bronchodilation test by repeating the pulmonary function test 15 minutes after inhaling $400 \mathrm{mg}$ of the bronchodilator salbutamol aerosol. Subjects allergic to salbutamol or resting heart rhythm higher than $100 \mathrm{bpm}$ were excluded.

According to the 2017 Global Chronic Obstructive Pulmonary Disease Action (GOLD) guidelines [1], we defined the diagnostic criteria for COPD as the post-bronchodilator FEV1/FVC ratio $<0.7$. The severity of limitation of lung function among patients of spirometry-confirmed COPD were classified according to the percentage of FEV1 in the predicted value (pv): mild (GOLD stage I: FEV1/pv $\geq 80 \%$ ), moderate (GOLD stage II: $50 \% \leq \mathrm{FEV} 1 / \mathrm{pv}<80 \%$ ), severe (GOLD stage III: $30 \% \leq \mathrm{FEV} 1 / \mathrm{pv}<50 \%$ ), and extremely severe (GOLD stage IV: FEV1/pv < 30\%). Patients who were diagnosed with COPD would have further chest X-ray examination and COPD Assessment Test (CAT) [11].

\section{Epidemiological investigation and exposure assessment}

Face-to-face surveys were conducted using a structured questionnaire to obtain patients' basic demographic information, knowledge of COPD, respiratory disease history, family disease history, and respiratory symptoms, exposure of smoking and other risk factors. According to the GOLD document [1], the main types of risk factors for COPD are as follows: "indoor biofuel exposure" is defined as households using biofuels for cooking or heating; "coal exposure" as the households using coal fuel for cooking or 
heating; and "workplace exposure to dust or chemicals" as the exposure in the workplaces for at least 12 months to dust in the air or harmful chemical gases.

The exposure levels of the air pollutants were detected by the 2018 environmental air quality monitors in each district. The indicators included the air quality index (AQI) and the ambient concentrations of six air pollutants including $\mathrm{PM}_{2.5}, \mathrm{PM}_{10}, \mathrm{SO}_{2}, \mathrm{NO}_{2}, \mathrm{CO}$, and $\mathrm{O}_{3}$. The original monitoring data was obtained from the China National Environmental Monitoring Center, including the daily 24h measurement values of 11 monitoring points throughout 2018. The means of the 8:00-20:00 measurement values were regarded as the daily measurement values and were used to calculate the average of the indicators throughout the whole year, as well as their annual minimum and maximum values, which were respectively assessed on their impact for COPD in regression models.

\section{Data processing and statistical analysis}

The original questionnaire data is entered into EpiData, exported to Excel format, and saved after data cleaning. Weighted by the gender-age ratio in the 2017 Shenzhen Population Survey [12], the standardized prevalence and $95 \%$ confidence intervals $(\mathrm{Cl})$ were estimated overall and for subgroups. The chi-square test was used to compare the differences in prevalence between groups, and the CochranArmitage trend test was used for trend analysis. Univariable logistic regression was used to assess the impact on COPD of demographic characteristics, personal and family disease history, and exposure of risk factors. Variables with a $p$ value $<0.2$ were included in the multivariable regression, and stepwise regression was used to include the variables. In the final model, variables with a $p$ value $<0.05$ were regarded to have significant correlation with COPD. Statistical analysis was performed using SPSS (version 20.0).

\section{Results}

\section{Basic characteristics}

A total of 4,157 people were investigated in the survey and 3591 (86.48\%) were included for analysis who had available data of both epidemiological data and pulmonary function tests. The participants included 1603 (44.6\%) males, the average age was $55.25 \pm 9.46$ years, the average body mass index (BMI) was $24.44 \pm 3.20 \mathrm{~kg} / \mathrm{m}^{2}$, and the average annual exposure to $\mathrm{PM}_{2.5}$ was $24.24 \pm 2.08 \mu \mathrm{g} / \mathrm{m}^{3}$. Low proportions of participants reported ever being diagnosed with other lung diseases, including 150 (3.27\%) with chronic bronchitis, $50(0.80 \%)$ with asthma, 66 (1.29\%) with tuberculosis, and $88(2.70 \%)$ who were hospitalized for lung diseases during childhood. Regarding exposure to smoking, a total of $556(20.19 \%)$ people were current-smokers, of which the vast majority $(531,95.50 \%)$ were men and only $25(4.50 \%)$ were women; $102(2.13 \%)$ participants reported that their mother smoked during pregnancy. In regard to the exposure to other risk factors, 669 (18.75\%) people were exposed to dust or chemicals in workplaces, $9(0.23 \%)$ people to biofuels at home, and $12(0.41 \%)$ people to coal at home. The basic demographic characteristics and family history of the study population were listed in Table 1. 


\section{Prevalence of COPD}

Measured by spirometry, 280 people were diagnosed with COPD, and the crude prevalence rate of COPD among residents over 40 years old was $7.79 \%(95 \% \mathrm{Cl} 6.94-8.72)$ in Shenzhen city. Adjusted by the age and gender, the standardized prevalence of COPD was estimated to be 5.92\% (4.05-8.34) (Table 2), and about 172,100 (117,800-242,300) residents over 40 years old suffered from COPD in Shenzhen (Figure 1). The age-standardized prevalence rate among men over 40 years old was $6.51 \%$ (4.48-9.09), which was higher than that among women of $5.39 \%$ (3.67-7.62), and the difference was statistically significant $(p<0.001)$. The prevalence showed an upward trend as the age increased (trend test, $p<0.001)$. The gender-standardized prevalence of COPD among residents aged 40-49, 50-59, 60-69 and over 70 years old were $4.30 \%$ (2.77-6.20), 7.28\% (5.20-9.75), 12.72\% (9.31-15.16), and 14.95\% (7.28-19.19), respectively (Table 1).

The prevalence of COPD also showed difference in different areas of Shenzhen. The crude prevalence in the central area was the highest, reaching 9.34\% (7.89-10.95), and lowest in the eastern region $(5.44 \%$, 3.14-8.69), of which the prevalence in Pingshan District was the lowest of only 3.51\% (Figure 2A). Residents in central area were elder than in northern or eastern areas, which probably lead to the higher crude prevalence of COPD. However, standardized estimates still indicated the discrepancy among COPD prevalence in different areas. The standardized prevalence in central, northern and eastern areas were, respectively, 7.59\% (5.02-10.93), 5.60\% (3.80-7.93), and 3.86\% (0.85-11.61) (Figure 2B).

\section{Risk factors for COPD}

To evaluate the impact on COPD of the air conditions including AQI and the ambient concentrations of six major air pollutants, we performed univariable logistic regression to include the annual average as well as the minimum and maximum values of each indicator (Table 3 ). The results showed that the maximum value of $\mathrm{PM}_{10}$, the average and minimum value of $\mathrm{SO}_{2}$, and the average value of $\mathrm{CO}$ were significantly correlated with COPD. After standardization by gender and age, the effect of the maximum value of $\mathrm{PM}_{10}$ and the minimum value of $\mathrm{SO}_{2}$ remained statistically significant. The risk of COPD increased by $3.8 \%(0.5-7.1)$ as the maximum concentration of $\mathrm{PM}_{10}$ increased every $10 \mu \mathrm{g} / \mathrm{m}^{3}$. For every $1 \mu \mathrm{g} / \mathrm{m}^{3}$ increase in the minimum concentration of $\mathrm{SO}_{2}$, the risk of COPD increased by $11.8 \%(2.4-22.1)$.

The results of univariable logistic regression on other risk factors showed that smoking, education level, medical insurance type, lung disease history, and environmental exposure were significantly correlated with COPD (Table 4). In the final multivariable logistic regression model, the risk of COPD increased by 1.206 (1.120-1.299) times as every 10 years of age increased, by 1.156 (1.053-1.270) times per every 1 $\mu \mathrm{g} / \mathrm{m}^{3}$ increase of the annual minimum air $\mathrm{SO}_{2}$ concentration; people who smoked greater than 20 packyears (OR 1.968, 95\% Cl 1.367-2.832), whose mother smoked during pregnancy (OR 1.881, 95\% Cl 1.039$3.405)$, or who had been diagnosed with chronic bronchitis (OR 1.733, 95\% Cl 1.036-2.900) or asthma (OR $4.920,95 \% \mathrm{Cl} 2.425-9.982)$ significantly had higher risk of COPD (Table 4). 


\section{Clinical features of COPD patients}

Among the 280 patients diagnosed with COPD, most $(221,78.93 \%)$ patients were classified as mild COPD (GOLD stage I), 46 (16.43\%) patients were moderate COPD (GOLD stage II), and only 13 cases (4.64\%) were severe COPD (GOLD stage III/IV). Among 235 patients who underwent COPD assessment test (CAT), 15 patients $(6.4 \%)$ reported no related symptoms, and the other 220 patients $(93.6 \%)$ reported either the respiratory symptoms (cough, sputum, sputum, chest tightness, wheezing, restricted activity) or nonrespiratory symptoms (restricted going-out, poor sleep, and fatigue). The above eight symptoms were evaluated on a scale of $0-5$, and the results showed that the median CAT score of these patients was five points (interquartile range 2-9 points). Among the investigated patients, $24.7 \%(58 / 235)$ had a total CAT score of $\geq 10$ points and were regarded to have severe symptoms, as defined by GOLD [13]. Lowering the thresholds to detect symptomatic patients, we found that $55.7 \%(131 / 235)$ patients had a total score of over five points, and $82.6 \%(194 / 235)$ had a total score of over two points, where patients were clinically considered to be symptomatic (Figure 3A).

Among patients with COPD of GOLD stage I, II, III or above, the proportions of patients with severe symptoms (CAT score $\geq 10$ ) were $18.6 \%, 38.5 \%$, and $69.2 \%$, respectively. About half of mild $(52.5 \%)$ and moderate $(59.0 \%)$ COPD patients gained a CAT score of $\geq$ five points, while most $(92.3 \%)$ severe patients could be detected under this threshold. The proportions of patients who were clinically considered to be symptomatic (CAT score $\geq 2$ ) were $79.8 \%, 89.7 \%$, and $100.0 \%$, respectively (Figure 3B). Nearly half of the patients $(44.3 \%, 104 / 235)$ reported at least four symptoms. The proportions of patients reporting $\geq$ four symptoms among mild, moderate and severe COPD were $42.6 \%, 43.6 \%$, and $69.2 \%$, respectively (Figure $\underline{3 C / D})$. The most frequently reported symptoms are cough (138,58.7\%), expectoration (134, 57.0\%), poor sleep $(131,55.7 \%)$, and fatigue $(123,52.3 \%)$ (Figure 3E). Among the above four most common symptoms, patients with any of them accounted for $88.5 \%(208 / 235)$.

\section{Discussion}

This cross-sectional survey estimated that the standardized prevalence of COPD among urban residents over 40 years old in Shenzhen is $5.92 \%$ (95\% Cl 4.05-8.34), which was greatly lower than the average level of $13.6 \%$ across China [5]. Risk factors including elder age, smoking, history of lung diseases, and exposure to higher ambient concentrations of $\mathrm{SO}_{2}$ were found significantly associated with the diagnosis of COPD. Most of the diagnosed patients had mild symptoms and were classified as GOLD stage I. Considering that the early intervention for mild COPD patients would have the most benefits [2], we suggest in resourceful city settings to screen COPD using spirometry in primary-care facilities to promptly detect early-stage patients and effectively control the disease progression or COPD-related mortality.

In our study, the prevalence of COPD among the urban populations over 40 years old in Shenzhen was far lower than the prevalence rate of $13.6 \%$ obtained from the 2014-2015 national epidemiological survey [5], and also lower than the global estimate in 2010 of 11.7\% [14]. The prevalence of COPD in other cities in China showed similar levels, such as $6.5 \%$ in Shanghai [6], 5.5\% in urban areas of Shanxi Province [6], 
or $6.0 \%$ in Heilongjiang Province [15]. More young populations in cities could be one of the reasons for the lower overall prevalence of COPD. Besides, we also observed a significant decrease in COPD prevalence among different age groups, especially among elderly populations $-12.7 \%$ and $14.9 \%$ in Shenzhen versus $21.2 \%$ and $35.5 \%$ nationally among people aged $60-69$ and aged $\geq 70$ years, respectively [16]. We assume that better air quality and improved indoor environment in cities have longterm benefits and prevent people from chronic lung diseases including COPD [17]. As statistics in our study, $18.75 \%$ of investigated people reported exposure to dust or chemicals at workplaces, and only $0.23 \%$ and $0.41 \%$ were, respectively, exposed to biomass or coal during cooking or heating in households. These figures were all extraordinarily lower than the national levels $(46.6 \%, 40.7 \%$, and $34.3 \%$, respectively) [5]. Smoking [18], the well-known risk factor for pulmonary diseases, also showed a lower level in Shenzhen than nationally (28.3\% versus $40.2 \%)$.

Of note, shown were differences in the prevalence of COPD in various regions of Shenzhen. The standardized prevalence in the central region (7.6\%) was almost twice that in the eastern coastal areas (3.9\%). The lower population density, fewer cars, and better air quality in the eastern region probably led to this difference. Though $\mathrm{PM}_{2.5}$, the main indicator for air quality, did not show a significant impact on COPD in our data, we found that exposure to higher ambient concentrations of $\mathrm{SO}_{2}$ increased the risk of COPD and its annual minimum value presented the most sensible impact. This result agreed with a recent observation from an Australian cohort, where the exposure to higher concentrations of $\mathrm{SO}_{2}$ was associated with the incidence of COPD in women of different age groups [19]. $\mathrm{SO}_{2}$ is one of the components of air pollutants resulting from industrial processes or fossil fuel combustion, which might resource from the crowded traffic in city centers or dense factories in Shenzhen. The spatial analysis in Mongolia showed that the ambient concentrations of $\mathrm{SO}_{2}$ and other traffic-related pollutants were higher in city centers or near main roads [20]. Other air pollutants might also increase the risk of COPD, as presented by a study in UK that higher concentrations of $\mathrm{PM}_{2.5}, \mathrm{PM}_{10}$, and $\mathrm{NO}_{2}$ were found significantly associated with higher prevalence of COPD [21]. Vehicle emissions could be the main sources of air pollution and potential reasons for respiratory diseases in city settings. To improve the environment in cities, policies have been implemented including constrain of vehicle population and optimization of transportation structure [22], and comprehensive strategies for the development of healthy cities were also urgently announced [23].

Most of the patients (78.93\%) diagnosed in this survey were mild COPD and classified as GOLD stage I. The proportion was even higher than that obtained from the national survey in 2014-2015 (56.4\%) [16]. COPD patients detected by screening in other countries are mainly moderate-level patients. For example, $30.6 \%$ and $51.4 \%$ of COPD patients diagnosed in a survey in Poland were classified as mild- (GOLD stage I) and moderate-level (GOLD stage II), respectively [24]. Early diagnosis and treatment of patients with mild COPD can more effectively control their lung function status and significantly reduce their progression and deterioration [25]. As recommended by GOLD [26], spirometry is considered a necessary tool for screening mild COPD patients, which is a basic tool for COPD diagnosis as well as the grading of lung function. In our survey, the proportion of people who have undergone spirometry before our 
investigation was very low, and even among COPD patients, the proportion was still less than $10 \%$. This indicated that the current screening in Shenzhen is insufficient to timely detect COPD patients in an early stage. For the purpose of early diagnosis and effective control, it is necessary to include spirometry in the routine examinations of people over 40 years old, which helps to find early-stage COPD patients and to promptly intervene, as suggested in Health Regulations in Shenzhen Special Economic Zone [27].

The CAT score can be used to effectively screen high-risk groups with respiratory symptoms or restricted daily activities [11], but the total CAT score of the diagnosed patients in this survey was generally low. Half of the patients obtained less than five points, suggesting that the threshold of CAT score should be lowered in screening COPD patients. For example, if the CAT total score is two or above, $82.6 \%$ of mild COPD patients would be recommended to further examinations for confirmation. Other studies $[28,29]$ agreed the CAT score useful in the COPD screening of patients with COPD, and Kon S. and his colleagues [30] also proposed that a reduction of over two points could evaluate the effect of the intervention in COPD patients. However, there were still some patients who had no self-reported symptoms or who had a total CAT score of fewer than two points. These patients can only rely on spirometry for screening.

This study only involved residents in one specific city of China where a large number of young people migrant from rural areas to this well-developed metropolis. Further studies are needed to characterize the prevalence of obstructive pulmonary diseases in other cities. Cost-effectiveness analysis will also support the implication of different screening strategies in different settings.

\section{Conclusions}

This cross-sectional survey found a relatively low prevalence of COPD among urban populations over 40 years old in Shenzhen. Spirometry and a low threshold of a two-point CAT score are recommended for COPD screening, and further effort including optimization of transportation and the industrial process is needed to improve environmental conditions in cities.

\section{Abbreviations}

COPD

Chronic obstructive pulmonary disease; CAT:COPD assessment test; IQR:Interquartile range; OR:odds ratio.

\section{Declarations}

\section{Ethics approval and consent to participate}

The epidemiological investigation and related tests and evaluations were conducted after receiving the signed informed consent from all the participants. This survey was reviewed and approved by the Ethics Committee of Shenzhen Center for Chronic Disease Control (No. SZCCC-2020-018-05-PJ). 


\section{Consent for publication}

Not applicable.

\section{Availability of data and materials}

The dataset analyzed during this study are included in this published article. The raw data of individuals used of this study are available from the corresponding author on reasonable request.

\section{Competing interests}

The authors declare that they have no competing interests.

\section{Funding}

This study was funded by Sanming project of Medicine in Shenzhen (SZSM201611030 to TW). The funder had no role in study design, data collection and analysis, or preparation of the manuscript.

\section{Authors' contributions}

$\mathrm{LJ}, \mathrm{HG}$, and WT designed and managed the study. LJ and CL collected, processed and cleaned the raw data; JY and QJ did the data analysis and interpretation. JY drafted the manuscript; LJ, LW, and QJ prepared the final article; all authors contributed to and reviewed the final version.

Acknowledgements: We thank the physicians of municipal- and district-level Centers for Chronic Disease Control in Shenzhen and public health teams of investigated communities for their work in this prevalence survey.

\section{References}

1. Vogelmeier CF, Criner GJ, Martinez FJ, Anzueto A, Barnes PJ, Bourbeau J, et al. Global Strategy for the Diagnosis, Management, and Prevention of Chronic Obstructive Lung Disease 2017 Report. GOLD Executive Summary. Am J Respir Crit Care Med. 2017;195(5):557-82.

2. Zhou Y, Zhong N, Li X, Chen S, Zheng J, Zhao D, et al. Tiotropium in Early-Stage Chronic Obstructive Pulmonary Disease. N Engl J Med. 2017;377(10):923-35.

3. Halpin DMG, Criner GJ, Papi A, Singh D, Anzueto A, Martinez FJ, et al. Global Initiative for the Diagnosis, Management, and Prevention of Chronic Obstructive Lung Disease. The 2020 GOLD Science Committee Report on COVID-19 and Chronic Obstructive Pulmonary Disease. Am J Respir Crit Care Med. 2021;203(1):24-36.

4. Zhou M, Wang H, Zeng X, Yin P, Zhu J, Chen W, et al. Mortality, morbidity, and risk factors in China and its provinces, 1990-2017: a systematic analysis for the Global Burden of Disease Study 2017. Lancet (London, England). 2019;394(10204):1145-58. 
5. Fang L, Gao P, Bao H, Tang X, Wang B, Feng Y, et al. Chronic obstructive pulmonary disease in China: a nationwide prevalence study. Lancet Respir Med. 2018;6(6):421-30.

6. Zhong N, Wang C, Yao W, Chen P, Kang J, Huang S, et al. Prevalence of chronic obstructive pulmonary disease in China: a large, population-based survey. Am J Respir Crit Care Med. 2007;176(8):753-60.

7. Chen X, Cheng J, Cao Y, Liu Y, Hu Y, Li Q, et al. Analysis of the impairment of pulmonary ventilation function and influencing factors in residents ( $>40$ year old) of Shenzhen city. Chinese J Prev Control Chronic Dis. 2017;25(01):21-5.

8. Shenzhen Statistics Bureau; NBS Survey Office in Shenzhen. Shenzhen Statistical Yearbook 2019. Beijing: China Statistics Press; 2019.

9. Shenzhen Meteorological Bureau. Shenzhen Climate Bulletin [Internet]. 2020. Available from: http://sztqb.sznews.com/attachment/pdf/202002/27/d545ba11-0af1-4730-a79562951a4aeee0.pdf

10. Shenzhen Municipal Ecological Environment Bureau. 2019 Shenzhen Municipal Environmental Status Bulletin. 2020; Available from: http://www.sz.gov.cn/zfgb/2020/gb1151/content/post_7574296.html

11. Jones PW, Harding G, Berry P, Wiklund I, Chen W-H, Kline Leidy N. Development and first validation of the COPD Assessment Test. Eur Respir J [Internet]. 2009;34(3):648-54. Available from: https://erj.ersjournals.com/content/34/3/648

12. Shenzhen Statistics Bureau, NBS Survey Office in Shenzhen. Shenzhen statistical yearbook 2017. Beijing: China Statistics Press; 2017.

13. Singh D, Agusti A, Anzueto A, Barnes PJ, Bourbeau J, Celli BR, et al. Global Strategy for the Diagnosis, Management, and Prevention of Chronic Obstructive Lung Disease: the GOLD science committee report 2019. Eur Respir J. 2019;53(5).

14. Adeloye D, Chua S, Lee C, Basquill C, Papana A, Theodoratou E, et al. Global and regional estimates of COPD prevalence: Systematic review and meta-analysis. J Glob Health. 2015;5(2):20415.

15. Han R, Zou J, Shen X, Wu C, Guo Y, Feng Z, et al. [The risk factors of chronic obstructive pulmonary disease in Heilongjiang province]. Chinese J Tuberc Respir Dis. 2015 Feb;38(2):93-8.

16. Wang C, Xu J, Yang L, Xu Y, Zhang X, Bai C, et al. Prevalence and risk factors of chronic obstructive pulmonary disease in China (the China Pulmonary Health [CPH] study): a national cross-sectional study. Lancet. 2018;391(10131):1706-17.

17. Faizan MA, Thakur R. Measuring the impact of household energy consumption on respiratory diseases in India. Glob Heal Res policy. 2019;4:10.

18. Biener Al, Decker SL, Rohde F. Prevalence and Treatment of Chronic Obstructive Pulmonary Disease (COPD) in the United States. JAMA. 2019;322(7):602.

19. Hendryx M, Luo J, Chojenta C, Byles JE. Air pollution exposures from multiple point sources and risk of incident chronic obstructive pulmonary disease (COPD) and asthma. Environ Res. 2019;179(Pt A):108783. 
20. Huang Y-K, Luvsan M-E, Gombojav E, Ochir C, Bulgan J, Chan C-C. Land use patterns and SO2 and NO2 pollution in Ulaanbaatar, Mongolia. Environ Res. 2013;124:1-6.

21. Doiron D, de Hoogh K, Probst-Hensch N, Fortier I, Cai Y, De Matteis S, et al. Air pollution, lung function and COPD: results from the population-based UK Biobank study. Eur Respir J. 2019;54(1):1802140.

22. Sun S, Jin J, Xia M, Liu Y, Gao M, Zou C, et al. Vehicle emissions in a middle-sized city of China: Current status and future trends. Environ Int. 2020;137:105514.

23. Guan W-J, Zheng X-Y, Chung KF, Zhong N-S. Impact of air pollution on the burden of chronic respiratory diseases in China: time for urgent action. Lancet (London, England). 2016;388(10054):1939-51.

24. Bednarek M, Maciejewski J, Wozniak M, Kuca P, Zielinski J. Prevalence, severity and underdiagnosis of COPD in the primary care setting. Thorax. 2008;63(5):402-7.

25. Guirguis-Blake JM, Senger CA, Webber EM, Mularski RA, Whitlock EP. Screening for Chronic Obstructive Pulmonary Disease: Evidence Report and Systematic Review for the US Preventive Services Task Force. JAMA. 2016;315(13):1378-93.

26. Vestbo J, Hurd SS, Agustí AG, Jones PW, Vogelmeier C, Anzueto A, et al. Global strategy for the diagnosis, management, and prevention of chronic obstructive pulmonary disease: GOLD executive summary. Am J Respir Crit Care Med. 2013;187(4):347-65.

27. Standing Committee of Shenzhen Municipal People's Congress. Health Regulations in Shenzhen Special Economic Zone. 2020.

28. Houben-Wilke S, Janssen DJA, Franssen FME, Vanfleteren LEGW, Wouters EFM, Spruit MA. Contribution of individual COPD assessment test (CAT) items to CAT total score and effects of pulmonary rehabilitation on CAT scores. Health Qual Life Outcomes [Internet]. 2018;16(1):205. Available from: https://doi.org/10.1186/s12955-018-1034-4

29. Jones PW, Tabberer M, Chen W-H. Creating scenarios of the impact of copd and their relationship to COPD assessment test (CAT ${ }^{\mathrm{TM}}$ ) scores. BMC Pulm Med [Internet]. 2011;11(1):42. Available from: https://doi.org/10.1186/1471-2466-11-42

30. Kon SSC, Canavan JL, Jones SE, Nolan CM, Clark AL, Dickson MJ, et al. Minimum clinically important difference for the COPD Assessment Test: a prospective analysis. Lancet Respir Med. 2014;2(3):195-203.

\section{Tables}


Table 1

Demographic characteristics and exposures of study participants

\begin{tabular}{|c|c|c|c|}
\hline & $\begin{array}{l}\text { Total } \\
(n=3591)\end{array}$ & $\begin{array}{l}\text { Men } \\
(n=1603)\end{array}$ & $\begin{array}{l}\text { Women } \\
(n=1988)\end{array}$ \\
\hline Age, $m \pm s d$ & $55.25 \pm 9.46$ & $55.11 \pm 9.75$ & $55.37 \pm 9.22$ \\
\hline \multicolumn{4}{|l|}{ Age, n (\%) } \\
\hline $40-49$ years & 1189 (65.89) & $571(67.55)$ & $618(63.90)$ \\
\hline $50-59$ years & $1140(20.62)$ & $464(20.43)$ & $676(20.86)$ \\
\hline $60-69$ years & 1012 (8.55) & $445(7.67)$ & $567(9.60)$ \\
\hline$\geq 70$ years & $250(4.94)$ & $123(4.35)$ & $127(5.64)$ \\
\hline \multicolumn{4}{|l|}{ Education level, n (\%) } \\
\hline Primary school or less & $735(14.07)$ & $225(10.17)$ & $510(18.79)$ \\
\hline Middle and high school & $2097(57.66)$ & $986(59.60)$ & $1111(55.32)$ \\
\hline College and higher & $757(28.27)$ & $392(30.24)$ & 365 (25.89) \\
\hline \multicolumn{4}{|l|}{ Years of residence in Shenzhen, $n(\%)$} \\
\hline $1-10$ & 1049 (23.19) & $433(21.86)$ & $616(24.79)$ \\
\hline$\geq 10$ & $2539(76.81)$ & 1168 (78.14) & $1371(75.21)$ \\
\hline \multicolumn{4}{|l|}{ Residence Region, n (\%) } \\
\hline Central Region & $1446(40.10)$ & $595(38.79)$ & $851(41.68)$ \\
\hline Eastern Region & $294(7.19)$ & $159(7.40)$ & $135(6.95)$ \\
\hline Northern Region & $1851(52.71)$ & $849(53.81)$ & $1002(51.37)$ \\
\hline \multicolumn{4}{|l|}{ Disease history, n (\%) } \\
\hline Mother smoked during pregnancy & $102(2.13)$ & $44(1.98)$ & $58(2.31)$ \\
\hline History of chronic bronchitis & $150(3.27)$ & $69(3.48)$ & $81(3.00)$ \\
\hline History of asthma & $50(0.80)$ & $26(0.79)$ & $24(0.81)$ \\
\hline History of tuberculosis & $66(1.29)$ & $39(1.86)$ & $27(0.60)$ \\
\hline Childhood hospitalization for pulmonary diseases & $88(2.70)$ & $40(3.11)$ & $48(2.21)$ \\
\hline
\end{tabular}

Note: Continuous variables were expressed as mean \pm standard variation $(\mathrm{m} \pm \mathrm{sd})$, and category data as counts (proportion). 


\begin{tabular}{|c|c|c|c|}
\hline & $\begin{array}{l}\text { Total } \\
(n=3591)\end{array}$ & $\begin{array}{l}\text { Men } \\
(n=1603)\end{array}$ & $\begin{array}{l}\text { Women } \\
(n=1988)\end{array}$ \\
\hline Exposure to dust or chemicals & $669(18.75)$ & $350(22.08)$ & $319(14.73)$ \\
\hline Indoor exposure to biomass & $9(0.23)$ & $3(0.22)$ & $6(0.23)$ \\
\hline Indoor exposure to coal & $12(0.41)$ & $2(0.15)$ & $10(0.72)$ \\
\hline \multicolumn{4}{|l|}{ Smoking history, n (\%) } \\
\hline Never smoker & $2690(71.52)$ & $745(50.11)$ & $1945(97.31)$ \\
\hline Former smoker & 337 (8.29) & $323(14.73)$ & $14(0.54)$ \\
\hline Current smoker & $556(20.19)$ & $531(35.17)$ & $25(2.16)$ \\
\hline \multicolumn{4}{|l|}{ Smoking (pack-years), n (\%) } \\
\hline None & $2690(79.01)$ & $745(60.28)$ & $1945(97.92)$ \\
\hline One to less than 20 & $189(7.94)$ & 178 (14.35) & $15(1.47)$ \\
\hline 20 or more & $447(13.04)$ & $432(25.37)$ & $11(0.60)$ \\
\hline $\mathrm{BMI}, \mathrm{m} \pm \mathrm{sd}$ & $24.44 \pm 3.20$ & $24.91 \pm 3.11$ & $24.91 \pm 3.11$ \\
\hline \multicolumn{4}{|l|}{ History of spirometry test, n (\%) } \\
\hline Yes & $271(7.56)$ & $147(9.73)$ & $124(4.95)$ \\
\hline No & $3201(92.44)$ & $1396(90.27)$ & $1805(95.05)$ \\
\hline Annual mean $\mathrm{PM}_{2.5}$ exposure $\left(\mu \mathrm{g} / \mathrm{m}^{3}\right), \mathrm{m} \pm \mathrm{sd}$ & $24.24 \pm 2.08$ & $24.20 \pm 2.14$ & $24.27 \pm 2.03$ \\
\hline
\end{tabular}


Table 2

Standardized prevalence of COPD in population aged 40 years or older

\begin{tabular}{|c|c|c|c|}
\hline & Total & Men & Women \\
\hline Total & $5.92(4.05-8.34)$ & $6.51(4.48-9.09)$ & $5.39(3.67-7.62)$ \\
\hline \multicolumn{4}{|l|}{ Age (years) } \\
\hline $40-49$ & $4.30(2.77-6.20)$ & $3.79(2.23-5.36)$ & $4.94(3.23-6.65)$ \\
\hline $50-59$ & $7.28(5.20-9.75)$ & 7.75 (5.32-10.19) & $6.71(4.82-8.60)$ \\
\hline $60-69$ & $12.72(9.31-15.16)$ & $15.86(12.46-19.25)$ & $9.70(7.26-12.13)$ \\
\hline$\geq 70$ & $14.95(7.28-19.19)$ & $20.53(13.39-27.67)$ & $9.76(4.60-14.92)$ \\
\hline$p$ for trend & $<0.001$ & $<0.001$ & 0.030 \\
\hline \multicolumn{4}{|l|}{ Education level } \\
\hline Primary school or less & $8.89(6.83-10.94)$ & $12.50(8.18-16.82)$ & $6.53(4.38-8.67)$ \\
\hline Middle and high school & $5.78(4.78-6.78)$ & $5.72(4.27-7.16)$ & $5.87(4.49-7.25)$ \\
\hline College and higher & $5.60(3.96-7.24)$ & $5.23(3.02-7.43)$ & $6.13(3.67-8.59)$ \\
\hline$p$ for trend & 0.040 & 0.010 & 0.47 \\
\hline \multicolumn{4}{|l|}{ Region } \\
\hline Central city & 7.59 (5.02-10.93) & $8.76(4.82-14.42)$ & $6.65(3.58-11.23)$ \\
\hline Eastern Region & $3.86(0.85-11.61)$ & $4.26(0.59-16.59)$ & $3.16(0.20-16.92)$ \\
\hline Northern Region & $5.60(3.80-7.93)$ & $5.70(3.25-9.18)$ & $5.41(3.01-8.97)$ \\
\hline$p$ for difference & 0.012 & 0.022 & 0.046 \\
\hline
\end{tabular}


Table 3

The impact of ambient air quality and the exposure to six air pollutants on COPD

\begin{tabular}{|c|c|c|c|c|c|c|}
\hline & \multirow[t]{2}{*}{$\begin{array}{l}\text { COPD } \\
\text { cases }\end{array}$} & \multirow[t]{2}{*}{$\begin{array}{l}\text { Non-COPD } \\
\text { cases }\end{array}$} & \multicolumn{2}{|c|}{ Univariable regression } & \multicolumn{2}{|c|}{$\begin{array}{l}\text { Age-gender-adjusted } \\
\text { regression }\end{array}$} \\
\hline & & & OR $(95 \% \mathrm{Cl})$ & $\begin{array}{l}P \\
\text { value }\end{array}$ & Adjusted OR & $\begin{array}{l}P \\
\text { value }\end{array}$ \\
\hline AQI_mean & $\begin{array}{l}46.45 \pm \\
4.28\end{array}$ & $46.56 \pm 4.30$ & $\begin{array}{l}0.944(0.709- \\
1.256)\end{array}$ & 0.692 & - & - \\
\hline AQI_min & $\begin{array}{l}13.83 \pm \\
1.45\end{array}$ & $13.90 \pm 1.42$ & $\begin{array}{l}0.692(0.288- \\
1.662)\end{array}$ & 0.410 & - & - \\
\hline AQI_max & $\begin{array}{l}170.47 \pm \\
8.81\end{array}$ & $\begin{array}{l}166.17 \pm \\
41.69\end{array}$ & $\begin{array}{l}1.026(0.996- \\
1.057)\end{array}$ & 0.096 & $\begin{array}{l}1.024(0.993- \\
1.056)\end{array}$ & 0.132 \\
\hline $\mathrm{PM}_{2.5-\text { mean }}$ & $\begin{array}{l}27.70 \pm \\
3.21\end{array}$ & $27.66 \pm 3.25$ & $\begin{array}{l}1.039(0.715- \\
1.511)\end{array}$ & 0.840 & - & - \\
\hline $\mathrm{PM}_{2.5-\mathrm{min}}$ & $4.64 \pm 0.98$ & $4.62 \pm 1.03$ & $\begin{array}{l}1.310(0.400- \\
4.290)\end{array}$ & 0.656 & - & - \\
\hline $\mathrm{PM}_{2.5-\max }$ & $\begin{array}{l}131.38 \pm \\
31.44\end{array}$ & $\begin{array}{l}127.78 \pm \\
33.75\end{array}$ & $\begin{array}{l}1.033(0.996- \\
1.072)\end{array}$ & 0.085 & $\begin{array}{l}1.031(0.993- \\
1.072)\end{array}$ & 0.112 \\
\hline $\mathrm{PM}_{10}$ mean & $\begin{array}{l}46.60 \pm \\
5.11\end{array}$ & $46.75 \pm 5.10$ & $\begin{array}{l}0.941(0.739- \\
1.198)\end{array}$ & 0.621 & - & - \\
\hline $\mathrm{PM}_{10 \_}$min & $\begin{array}{l}10.20 \pm \\
2.35\end{array}$ & $10.12 \pm 2.40$ & $\begin{array}{l}1.137(0.687- \\
1.881)\end{array}$ & 0.618 & - & - \\
\hline $\mathrm{PM}_{10-\mathrm{max}}$ & $\begin{array}{l}184.33 \pm \\
38.67\end{array}$ & $\begin{array}{l}178.65 \pm \\
39.11\end{array}$ & $\begin{array}{l}1.037(1.006- \\
1.070)\end{array}$ & 0.020 & $\begin{array}{l}1.038(1.005- \\
1.071)\end{array}$ & 0.022 \\
\hline $\mathrm{SO}_{2-}$ mean & $7.37 \pm 1.13$ & $7.20 \pm 1.22$ & $\begin{array}{l}1.123(1.014- \\
1.245)\end{array}$ & 0.026 & $\begin{array}{l}1.098(0.986- \\
1.222)\end{array}$ & 0.090 \\
\hline $\mathrm{SO}_{2-} \min$ & $2.82 \pm 1.45$ & $2.49 \pm 1.34$ & $\begin{array}{l}1.184(1.088- \\
1.288)\end{array}$ & $\begin{array}{l}< \\
0.001\end{array}$ & $\begin{array}{l}1.118(1.024- \\
1.221)\end{array}$ & 0.013 \\
\hline $\mathrm{SO}_{2-} \max$ & $\begin{array}{l}19.23 \pm \\
4.73\end{array}$ & $18.69 \pm 4.87$ & $\begin{array}{l}1.023(0.998- \\
1.048)\end{array}$ & 0.077 & $\begin{array}{l}1.024(0.998- \\
1.050)\end{array}$ & 0.076 \\
\hline $\mathrm{NO}_{2}$ mean & $\begin{array}{l}31.30 \pm \\
5.52\end{array}$ & $31.11 \pm 5.50$ & $\begin{array}{l}1.006(0.984- \\
1.029)\end{array}$ & 0.579 & $\begin{array}{l}1.014(0.992- \\
1.038)\end{array}$ & 0.219 \\
\hline $\mathrm{NO}_{2-}$ min & $6.55 \pm 3.24$ & $6.27 \pm 3.42$ & $\begin{array}{l}1.024(0.989- \\
1.060)\end{array}$ & 0.181 & $\begin{array}{l}1.025(0.988- \\
1.064)\end{array}$ & 0.192 \\
\hline $\mathrm{NO}_{2-} \max$ & $\begin{array}{l}114.91 \pm \\
45.90\end{array}$ & $\begin{array}{l}110.33 \pm \\
47.02\end{array}$ & $\begin{array}{l}1.002(0.999- \\
1.005)\end{array}$ & 0.117 & $\begin{array}{l}1.003(1.000- \\
1.005)\end{array}$ & 0.053 \\
\hline
\end{tabular}

Note: The unit of each air pollutant is $\mu \mathrm{g} / \mathrm{m}^{3}$. The odds ratios (OR) were calculated as AQI, $P M_{2.5}$, $\mathrm{PM}_{10}$ increased every 10 units, $\mathrm{SO}_{2}, \mathrm{NO}_{2}, \mathrm{O}_{3}$ every 1 unit, and $\mathrm{CO}$ every 0.01 -unit change. 


\begin{tabular}{|c|c|c|c|c|c|c|}
\hline & \multirow[t]{2}{*}{$\begin{array}{l}\text { COPD } \\
\text { cases }\end{array}$} & \multirow[t]{2}{*}{$\begin{array}{l}\text { Non-COPD } \\
\text { cases }\end{array}$} & \multicolumn{2}{|c|}{ Univariable regression } & \multicolumn{2}{|c|}{$\begin{array}{l}\text { Age-gender-adjusted } \\
\text { regression }\end{array}$} \\
\hline & & & OR $(95 \% \mathrm{Cl})$ & $\begin{array}{l}P \\
\text { value }\end{array}$ & Adjusted OR & $\begin{array}{l}P \\
\text { value }\end{array}$ \\
\hline $\mathrm{O}_{3}$ mean & $\begin{array}{l}66.73 \pm \\
4.00\end{array}$ & $67.22 \pm 4.18$ & $\begin{array}{l}0.972(0.944- \\
1.001)\end{array}$ & 0.057 & $\begin{array}{l}0.976(0.947- \\
1.007)\end{array}$ & 0.126 \\
\hline $\mathrm{O}_{3-} \min$ & $5.98 \pm 2.58$ & $6.14 \pm 2.59$ & $\begin{array}{l}0.977(0.932- \\
1.025)\end{array}$ & 0.346 & - & - \\
\hline $\mathrm{O}_{3} \_\max$ & $\begin{array}{l}190.84 \pm \\
10.36\end{array}$ & $\begin{array}{l}191.58 \pm \\
10.45\end{array}$ & $\begin{array}{l}0.993(0.982- \\
1.005)\end{array}$ & 0.252 & - & - \\
\hline CO_mean & $0.64 \pm 0.02$ & $0.64 \pm 0.02$ & $\begin{array}{l}1.089(1.018- \\
1.164)\end{array}$ & 0.013 & $\begin{array}{l}1.062(0.996- \\
1.133)\end{array}$ & 0.067 \\
\hline CO_min & $0.26 \pm 0.09$ & $0.26 \pm 0.09$ & $\begin{array}{l}0.999(0.986- \\
1.012)\end{array}$ & 0.896 & - & - \\
\hline CO_max & $1.39 \pm 0.31$ & $1.38 \pm 0.31$ & $\begin{array}{l}1.001(0.997- \\
1.005)\end{array}$ & 0.740 & - & - \\
\hline \multicolumn{7}{|c|}{$\begin{array}{l}\text { Note: The unit of each air pollutant is } \mu \mathrm{g} / \mathrm{m}^{3} \text {. The odds ratios (OR) were calculated as AQI, } \mathrm{PM}_{2.5} \text {, } \\
\mathrm{PM}_{10} \text { increased every } 10 \text { units, } \mathrm{SO}_{2}, \mathrm{NO}_{2}, \mathrm{O}_{3} \text { every } 1 \text { unit, and } \mathrm{CO} \text { every } 0.01 \text {-unit change. }\end{array}$} \\
\hline
\end{tabular}


Table 4

Risk factors for COPD in age-and-gender adjusted logistic regression and the multivariable model

\begin{tabular}{|c|c|c|c|c|c|c|}
\hline & \multirow{2}{*}{$\begin{array}{l}\text { COPD } \\
\text { cases } \\
(n= \\
280)\end{array}$} & \multirow{2}{*}{$\begin{array}{l}\text { Non-COPD } \\
\text { cases } \\
(n=3311)\end{array}$} & \multicolumn{2}{|c|}{$\begin{array}{l}\text { Age and sex-adjusted } \\
\text { regression }\end{array}$} & \multicolumn{2}{|l|}{$\begin{array}{l}\text { Multivariable } \\
\text { regression }\end{array}$} \\
\hline & & & OR $(95 \% \mathrm{Cl})$ & $\begin{array}{l}P \\
\text { value }\end{array}$ & OR $(95 \% \mathrm{Cl})$ & $\begin{array}{l}P \\
\text { value }\end{array}$ \\
\hline Male & $\begin{array}{l}151 \\
(53.9)\end{array}$ & $\begin{array}{l}1452 \\
(43.9)\end{array}$ & $\begin{array}{l}1.514(1.183- \\
1.937)\end{array}$ & 0.001 & $\begin{array}{l}1.270 \\
(0.941- \\
1.712)\end{array}$ & 0.118 \\
\hline Age (per 10 years) & $\begin{array}{l}59.2 \pm \\
9.2\end{array}$ & $54.9 \pm 9.4$ & $\begin{array}{l}1.269(1.186- \\
1.356)\end{array}$ & $<0.001$ & $\begin{array}{l}1.206 \\
(1.120- \\
1.299)\end{array}$ & $<0.001$ \\
\hline $\begin{array}{l}\text { Air } \mathrm{SO}_{2} \text { minimum } \\
\text { exposure }\end{array}$ & $\begin{array}{l}2.82 \pm \\
1.45\end{array}$ & $2.49 \pm 1.34$ & $\begin{array}{l}1.120(1.026- \\
1.224)\end{array}$ & 0.012 & $\begin{array}{l}1.156 \\
(1.053- \\
1.270)\end{array}$ & 0.002 \\
\hline $\begin{array}{l}\text { Mother smoked during } \\
\text { pregnancy }\end{array}$ & $16(6.1)$ & $86(2.7)$ & $\begin{array}{l}2.084(1.194- \\
3.638)\end{array}$ & 0.010 & $\begin{array}{l}1.881 \\
(1.039- \\
3.405)\end{array}$ & 0.037 \\
\hline $\begin{array}{l}\text { History of chronic } \\
\text { bronchitis }\end{array}$ & $\begin{array}{l}30 \\
(10.8)\end{array}$ & $120(3.7)$ & $\begin{array}{l}2.638(1.717- \\
4.053)\end{array}$ & $<0.001$ & $\begin{array}{l}1.733(1.036- \\
2.900)\end{array}$ & 0.036 \\
\hline History of asthma & $20(7.2)$ & $30(0.9)$ & $\begin{array}{l}6.607(3.639- \\
11.996)\end{array}$ & $<001$ & $\begin{array}{l}4.920 \\
(2.425- \\
9.982)\end{array}$ & $<0.001$ \\
\hline $\begin{array}{l}\text { Smoking } \geq 20 \text { pack- } \\
\text { years }\end{array}$ & $\begin{array}{l}68 \\
(24.3)\end{array}$ & $488(14.8)$ & $\begin{array}{l}2.080(1.481- \\
2.921)\end{array}$ & $<.001$ & $\begin{array}{l}1.968 \\
(1.367- \\
2.832)\end{array}$ & $<0.001$ \\
\hline
\end{tabular}

\section{Figures}
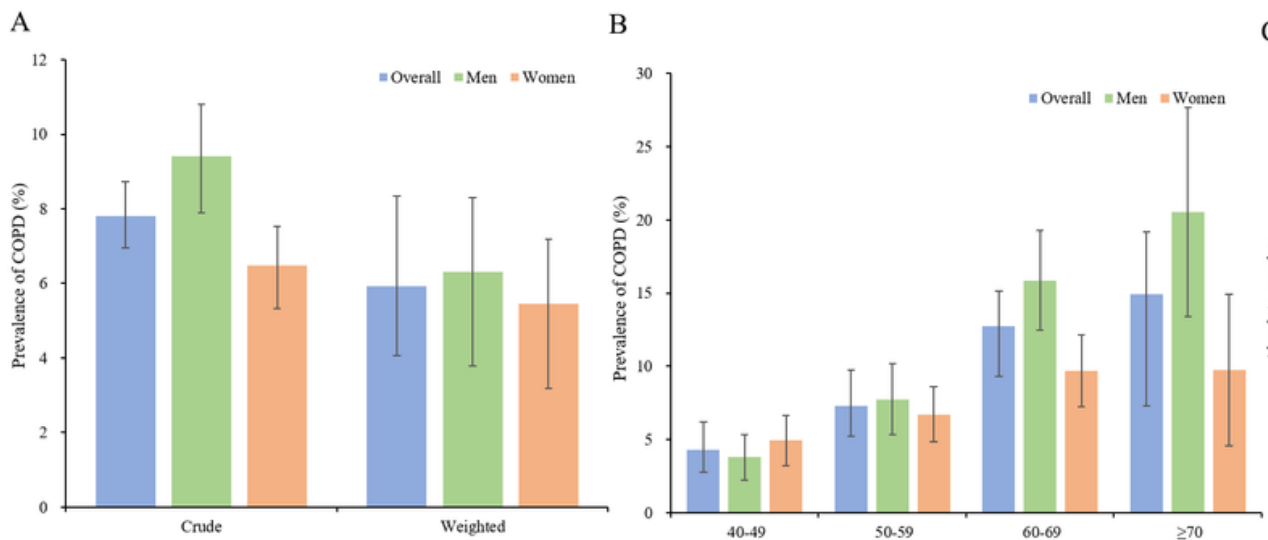

C

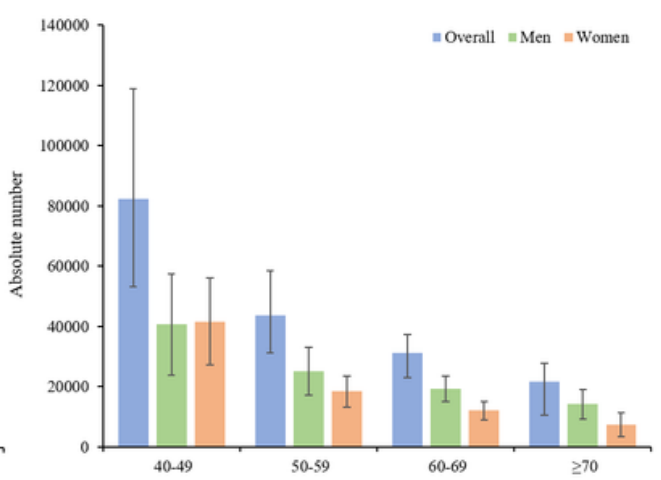

Figure 1 
The prevalence of COPD and the estimated number of patients by gender and age group. (A) Total prevalence and standardized prevalence of people over 40 years old; (B) Standardized prevalence of different age groups Disease rate; (C) Estimated number of patients in different age groups.
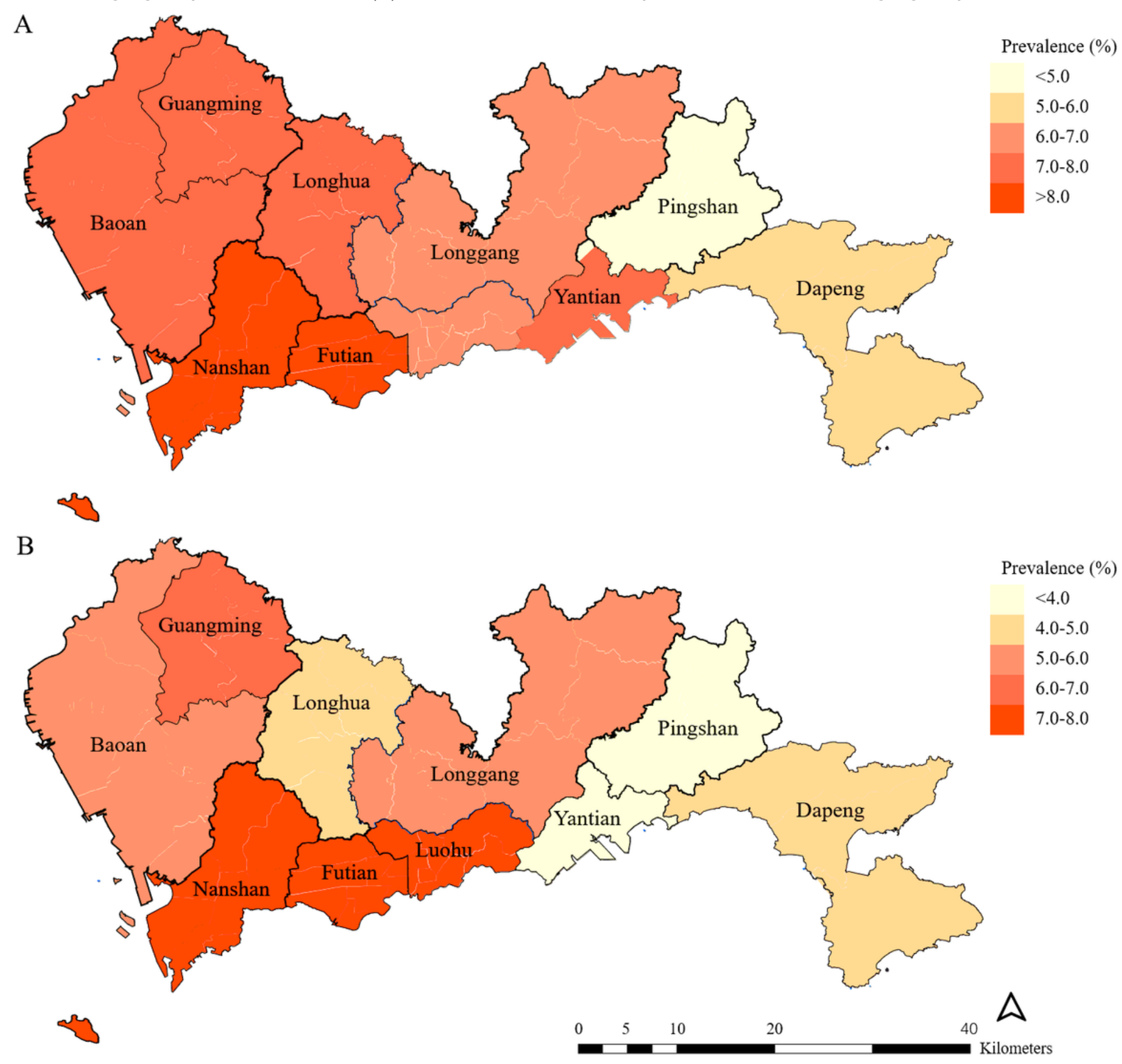

Figure 2

Crude prevalence (A) and standardized prevalence (B) by district. The central region Nanshan, Futian, and Luohu districts; the northern region includes Baoan, Guangming, Longhua, and Longgang districts; the eastern region includes Yantian, Pingshan, and Dapeng districts. Note: The designations employed and the presentation of the material on this map do not imply the expression of any opinion whatsoever on the part of Research Square concerning the legal status of any country, territory, city or area or of its 
authorities, or concerning the delimitation of its frontiers or boundaries. This map has been provided by the authors.

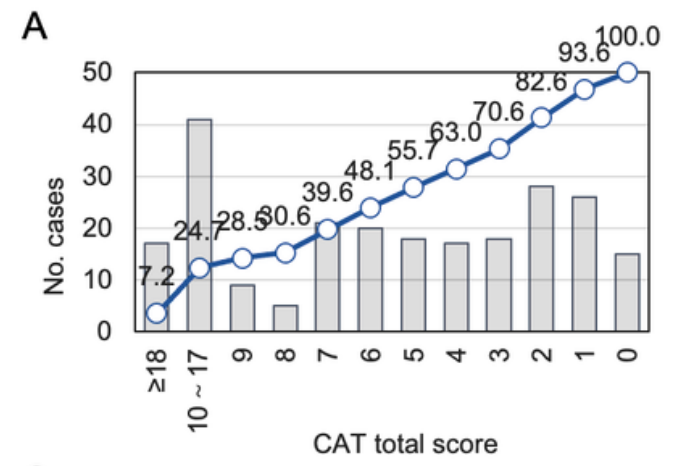

C
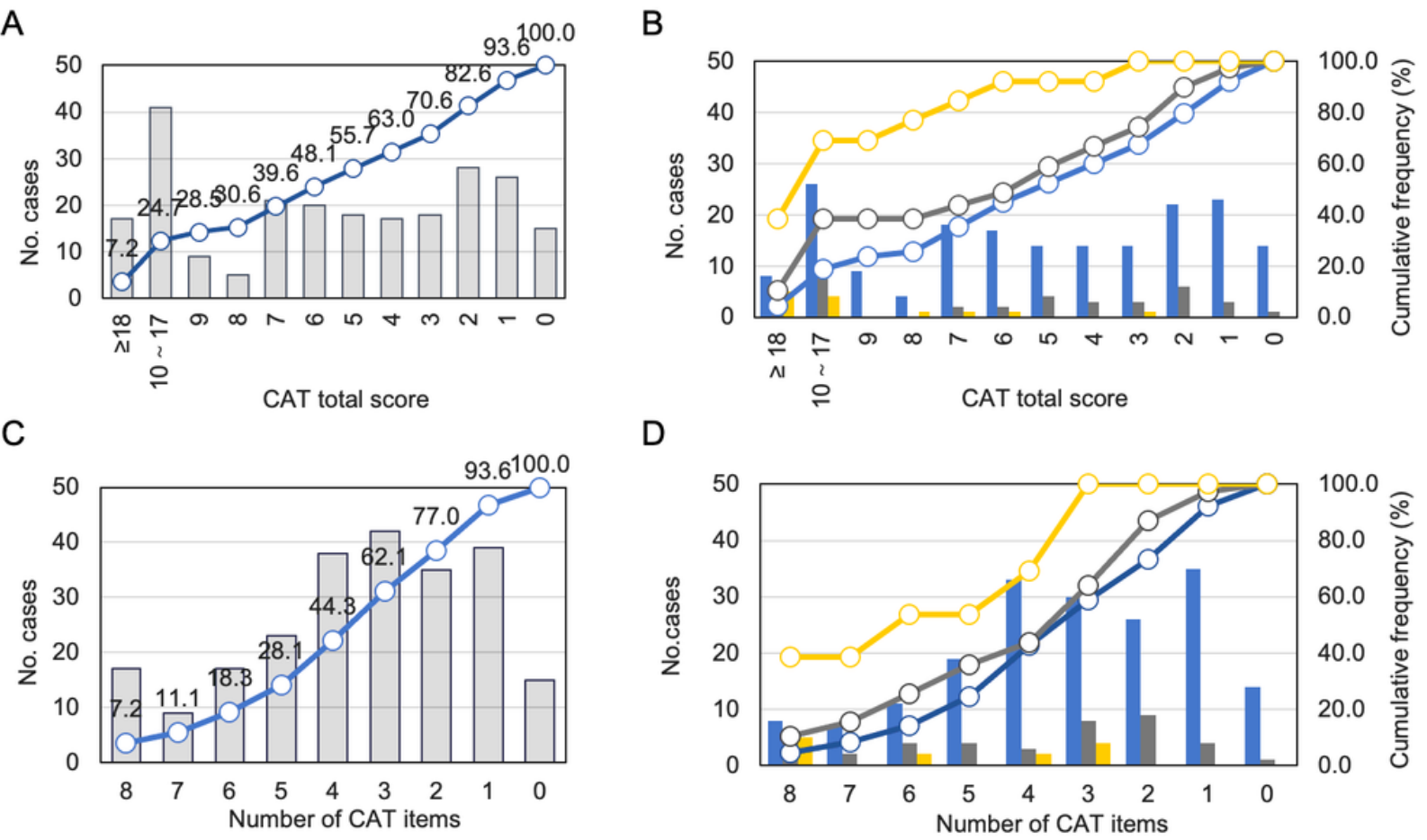

D

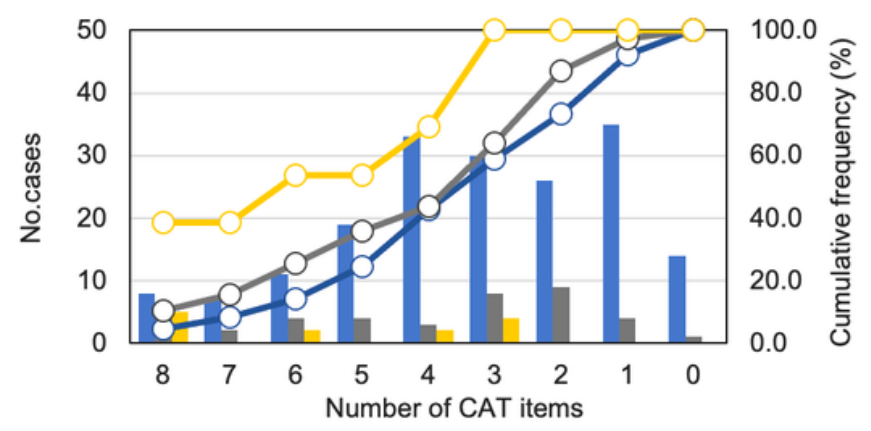

E

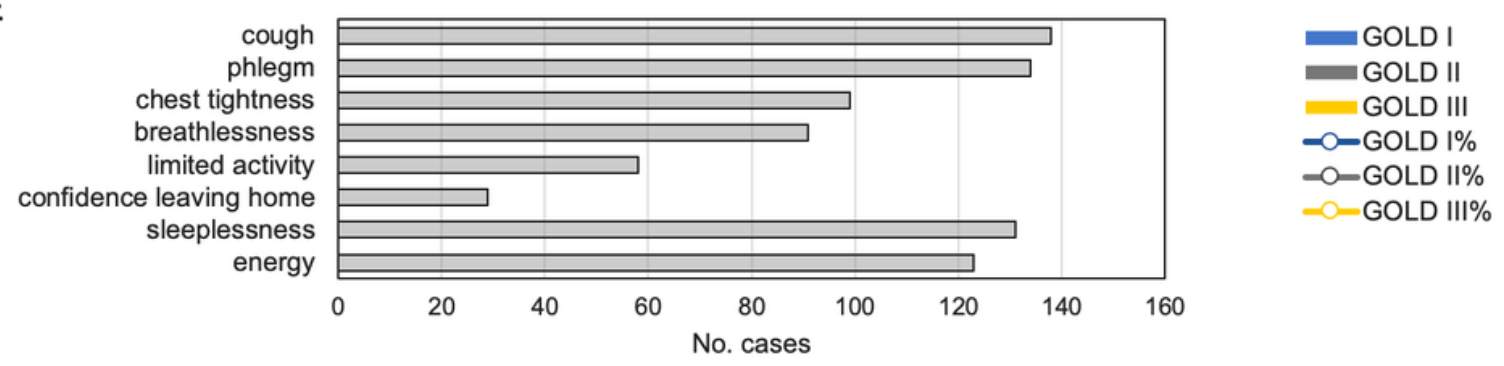

Figure 3

Related symptoms and COPD Assessment test (CAT) score of COPD patients. The total proportion of symptomatic patients whose CAT score and total score are higher than each threshold (A) and the stratification by GLOD level (B); cumulative proportions of patients reporting different numbers of CAT items (C) and the stratified by GLOD levels (D); (E) the number of people reporting various CAT items. 